\title{
Yükseköğretimde Öğrenci Sadakâti Ölçeği: Uyarlama, Dil Geçerliği ve Faktör Yapısının İncelenmesi
}

\author{
Arş. Gör. Dr. Mithat KORUMAZ* \\ Yıldız Teknik Üniversitesi, Eğitim Fakültesi, Davutpaşa Kampüsü, İstanbul / Türkiye
}

Arş. Gör. Esra TEKEL

Yıldız Teknik Üniversitesi, Eğitim Fakültesi, Davutpaşa Kampüsü, İstanbul / Türkiye

\section{$\ddot{O} z$}

Bu çalı̧̧manın amacı, Öğrenci Sadakâti Ölçeğini (Helgesen ve Nesset, 2007) Türkçeye uyarlayarak, geçerlik ve güvenirlik çalışmalarını yapmaktır. Çalışmada üç farklı örneklem grubu kullanılmıştır. İlk olarak ölçeğin dilsel eşdeğerliğini sağlamak amac1yla lisans eğitimini İngilizce öğretmenliğinde tamamlamış ve eğitim yönetimi ve denetimi alanında doktora aşamasında olan beş kişi yer almıştır. İkinci örneklemde ise ölçeğin açımlayıcı faktör analizi ve güvenirlik çalışmaları için Yıldız Teknik Üniversitesi, Eğitim Fakültesi’nde öğrenim görmekte olan 270 öğrenci yer almıştır. Son olarak ise Türkçeye uyarlanan, yeni ölçekte önerilen modelin uygunluğunu test etmek için yapılan doğrulayıcı faktör analizi için aynı üniversiteden 247 öğrenci örnekleme dâhil edilmiştir. Çalışmada, ilk olarak, ölçek maddeleri Türkçeye çevrilmiş ve çeviri geçerliliği incelenmiş; daha sonra da Türkçe ölçek formunun dil ve anlam, içerik geçerliği, madde-toplam ve madde-kalan korelasyonları, doğrulayıcı faktör analizi ve

* Sorumlu Yazar. Tel: +90 2123834820 E-posta: mithatkorumaz@ hotmail.comＯRCiD:0000-0003-1800-7633

(C) 2017 Kalem Eğitim ve Sağlık Hizmetleri Vakfi. Bütün Hakları Saklıdır. ISSN: 2146-5606 
alt ölçekler arasındaki korelasyonlar incelenmiştir. Orijinal ölçekte imkânlar (facilities), hizmet kalitesi (service quality), doyum (satisfaction), okulun imajı (image of university college), çalışma alanının imajı (image of study program) ve sadakât (loyalty) olarak belirlenen faktörlerin yapılan açımlayıcı faktör analizi sonucunda Türk kültürüne ve Türkiye'deki yükseköğretim sisteminin yapısına paralellik gösterecek şekilde farklı faktörlere dağıldığı görülmüştür. Bu çalışmanın sonuçlarına göre “Öğrenci Sadakâti Ölçeği”nin faktörleri, fakültenin imkânları, alınan hizmet kalitesi, hizmet kalitesi, sadakât, çalışma alanının imajı, okulun imajı olarak yeniden belirlenmiştir. Ayrıca ölçeğin geçerlik ve güvenirlik analiz sonuçlarının kabul edilebilir bir düzeyde olduğu görülmüştür.

Anahtar Kelimeler: Dil geçerliği; Faktör yapısı; Öğrenci sadakâti ölçeği; Uyarlama; Yükseköğretim.

\title{
Student Loyalty Scale for Higher Education: Adaptation, Investigating Factor Structure and Language Validity
}

\begin{abstract}
The purpose of this study is to adopt "Student Loyalty Scale" developed by Helgesen and Nesset (2007) into Turkish by providing validity and reliability of it. The researchers created three different group of participants for the study. The first group consisted of five experts in educational administration and supervision who completed undergraduate education in English Language Teaching. This group participated in the study for determining language equivalence of the items in the scale. The second group which was constituted for exploratory factor analysis consisted of 270 volunteer students who were students at college of education in Yildiz Technical University, İstanbul. Lastly the third group which was constituted for confirmatory factor analysis of adopted Turkish scale form consisted of 247 students from different faculties in the same university. The first step of the analysis was to translating items into target language (Turkish) and translation validity was tested. Then researchers investigated content, language and meaning validity of translated scale form, calculated item total and item correlation, run exploratory and confirmatory factor analysis and tested reliability of the scale with Cronbach alpha coefficient. The original scale has six factors as facilities, service quality, satisfaction, image of University College, image of study program and loyalty. As a result
\end{abstract}


exploratory factor analysis indicated that factor loadings have differentiated the scale which seems very suitable for the Turkish culture and higher education system. New factors has named as facilities of the faculty, outsource service quality, service quality, loyalty, image of study program, image of university. The researchers tried to conserve the concepts of the original scale wile naming the factors.

Keywords: Adaptation; Higher education; Language validity; Factor structure; Student loyalty scale.

\section{Extended Summary}

\section{Purpose}

The great variety of alternatives have forced people to make preferences every day. Therefore preferences have been the fundamental determinants of our daily life since industrial revolution. The modern world of organizations has focused on the direction of people preferences. Fornell, Johnson, Anderson, Cha and Bryant (1996) stated that preferability of a product or a service is determined by satisfaction from the service, commitment or loyalty. This kind of behavior has been conceptualized as "customer loyalty" which means that in spite of all of the efforts for effecting individuals' preferences people have been deeply loyal to the service or the product (Oliver, 1997). Therefore, it is possible to say that loyalty of the individuals can be crucial for the organizations of this thirty years (Lam, Shankar, Erramilli and Murthy, 2004; Reichheld, 1996).

In view of the expectations of the students from their universities, it can be concluded that student loyalty is getting more and more importance for new generation higher institutions (Hening-Thurau, Larger and Hansen, 2001). Higher education is focus point of the whole society because the results of its service effect all elements of the society (Helgesen and Nesset, 2007; Martensen, Gronholdt, Eskildsen and Kristensen, 2000). Raising importance of the student loyalty has pressured higher education institutions to interest with this issue. Some of the studies have been investigated the reasons, dimensions and results of the student loyalty up to now. Helgesen and Nesset (2007) have developed a scale to determine the level of student loyalty. The purpose of this study is to adopt "Student Loyalty Scale" developed by Helgesen and Nesset (2007) into Turkish culture by providing validity and reliability of it. 


\section{Method}

This quantitative research aimed at adopting student loyalty scale developed by Helgesen ve Nesset (2007) which is seven point Likert scale has six factors as facilities, service quality, satisfaction, image of University College, image of study program and loyalty with 25 item total.

\section{Participants}

The researchers created three different groups of participants for the study. The first group consisted of five experts in educational administration and supervision who completed undergraduate education in English Language Teaching. This group participated in the study for determining language equivalence of the items in the scale. The second group which was constituted for exploratory factor analysis consisted of 270 volunteer students who were students at college of education in Ylddz Technical University, İstanbul. Lastly the third group which was constituted for confirmatory factor analysis of adopted Turkish scale form consisted of 247 students from different faculties in the same university.

\section{Data Collection Tools}

The data of the study were collected with student loyalty scale developed by Helgesen and Nesset (2007). This scale has been developed in Aalesund University in Norway to determine the level of student loyalty.

\section{Process}

In the first step of the research process, five experts in educational administration and supervision who completed undergraduate education in English Language Teaching translated original items into Turkish independent of each other. Then they came together and they decided on the items together. They created translation suitability form which contains both original and translated items. In the second step, researchers run exploratory factor analysis to provide structure validity of the scale. In third step, researchers run confirmatory factor analysis to determine conformity of both factors and items. Finally internal consistency of the scale has been tested with Cronbach alpha coefficient.

\section{Results}

Language equivalence test results showed that 20 of the 25 items had 
nine or more mean for language equivalence. The least mean was $[\overline{\mathrm{X}}=6.75$; $s s=3.94]$ of the item 22. It is stated "Perception of the study among employers". On the other hand items, 7, 9, 10, 12, 14, 18, 23 and 24 has got $[\bar{X}=10.0$; $\mathrm{ss}=0.00$ ] the highest scores.

Kaiser Meyer Olkin=.837 and Barlet $\left(\chi^{2}=1847.40, p<.01\right)$ test results indicated that data was suitable for exploratory factor analysis. Varimax rotation method was preferred because scale had multiple factor structure. Factor analysis with Varimax rotation indicated that scale has 6 factors and variance explained by the scale was $72 \%$. Despite the fact that six factor structure was the same with the original scale, some items distributed in different factors as suitable for the Turkish culture and higher education structure.

Chi-Square $\left(\chi^{2}\right)$ value and significance level $\left[\chi^{2}=604.6, d f=260\right]$ and low Chi-Square value $\left(\chi^{2}\right)$ was calculated as $\left[\chi^{2} / d f=2.3\right]$. Good fit indexes [RMSEA $=.07, \mathrm{AGFI}=.80, \mathrm{CFI}=.90, \mathrm{NFI}=.84, \mathrm{GFI}=.84]$ confirmed the modelled structure of the factors (Jöreskog and Sörbom, 2001; Kline, 2005). The relationship between factors in the scale which was confirmed was tested with Pearson correlation. And results showed that relationship between factors varied between .124 and .500 . Finally, reliability of the scale was tested with Cronbach alpha coefficient. Cronbach alpha values varied between .463 and .914. Scale total Cronbach alpha coefficient was found as .715.

\section{Discussion}

The original student loyalty scale has six factors as facilities, service quality, satisfaction, image of University College, image of study program and loyalty. As a result exploratory factor analysis indicated that factor loadings have differentiated the scale which seems very suitable for the Turkish culture and higher education system. New factors has named as facilities of the faculty, outsource service quality, service quality, loyalty, image of study program, image of university. The researchers tried to conserve the concepts of the original scale wile naming the factors. The new adopted student loyalty scale is a valid and reliable scale to use determine student loyalty level in Turkish higher education institutions. 


\section{Giriş}

Tercihler, sanayi devriminden bu yana toplumsal hayatın temel belirleyicileri konumundadır. İhtiyaçtan çok daha fazla sayıda ve türde ürünün üretilmesi bireyleri her ihtiyacını karşılamada yeni tercihler yapmaya itmektedir. Dolayısıyla bireylerin tercihlerinin hangi yönde olacağı, tercihleri belirleyen temel değişkenlerin ne olduğu, ürünün ya da hizmetin neden tercih edilir olduğu gibi pek çok soru örgüt alan yazınına marka, imaj, rekabet, sürdürülebilirlik, memnuniyet, sadakât ve bağl1lık gibi sayısız kavramın taşınması ile sonuçlanmıştır. Fornell ve arkadaşlarına (1996) göre ortaya çıkarılan ürün ya da hizmetin tercih edilirliğini belirleyen bu kavramların en öne çıkanları ürün ya da hizmete karşı duyulan memnuniyet, bağlılık ve sadakâttir. Bunun yanında ürünü ya da hizmeti ortaya çıkaran marka ve bu markanın imajı da memnuniyet, bağlılık ve sadakâtin temel belirleyicilerindendir (Brown, Dacin, Pratt ve Whetten, 2006; Chun, 2005). Bireylerin ürüne veya hizmete yönelik tercihleri "müşteri sadakâti" olarak kavramsallaşt1rılmıştır. Müşteri sadakâti kavramı, bütün pazarlama çabaları ve durumsal tesirlere rağmen bireyin tercih ettiği bir ürün ya da hizmeti yeniden tercih etmeye yönelik gösterdiği derin bağlllık (Oliver, 1997); ya da bir ürüne, hizmete, marka ya da örgüte derin sadakât ve genel bir bağll1ık (Lam ve ark., 2004) olarak tanımlanmaktadır. Bu açıdan değerlendirildiğinde bir örgütün ortaya koyduğu ürünün ya da hizmetin bu ürün ya da hizmetten faydalanan kişiler tarafından sürekli bir biçimde tercih ediliyor olması, örgütün hayatî fonksiyonları bakımından büyük önem taşımaktadır (Reichheld, 1996).

Tercih edilirliğin sürekliliği eğitim örgütleri için de büyük önem taşır. Eğitim örgütleri için düşünüldüğünde "öğrenci sadakâtinin" sağlanmasının bir zorunluluk hâline geldiği söylenebilir (Hening-Thurau, Larger ve Hansen, 2001). Özellikle yükseköğretim seviyesinde eğitim örgütlerinin sunduğu hizmetten başta öğrenciler olmak üzere devlet, aileler, işverenler ve toplumun büyük bir kesimi faydalanmaktadır. Dolayısıyla bütün bu kesimler yükseköğretim kurumları için "müşteri” olarak tanımlanabilir (Helgesen ve Nesset, 2007; Martensen ve ark., 2000). Bu bağlamda Köse (2012) öğrenci sadakâtini, öğrencinin üniversitesine ve verdiği hizmete olan bağl1lı̆̆ olarak tanımlamıştır. Öğrenci sadakâti kavramının bu noktada müşteri sadakâti kavramından ayrıldığı söylenebilir. Müşteri sadakâtinde memnuniyet, hizmet ya da üründen doğrudan faydalanan kişi ile ilgiliyken; öğrenci sadakâti, sadece eğitim örgütlerinin sundukları eğitim hizmetinin kendisi ile değil; aynı 
zamanda eğitim hizmetinden dolaylı olarak etkilenen bütün paydaşların etkisi ile oluşan tutumlarla ilgili bileşenleri ve davranışsal bileşenleri içerir (Marzo-Navarro, Pedraja-Iglesias ve Rivera-Torres, 2005). Helgesen ve Nesset'e (2007) göre tutumlarla ilgili bileşenler üç boyuttan oluşmaktadır. Bu boyutlar bilişsel, duyuşsal ve psiko-motor etkinlikleri kapsar. Davranışsal bileşenler ise öğrencilerin alışkanlıklarını göz önünde bulundurarak aldıkları eğitime duydukları sadakâtle ilgili verdikleri kararları kapsamaktadır. Bir yükseköğretim kurumunun bütün çevresel etkilere rağmen en öncelikli amaçlarından biri öğrencilerinin sadakâtlerini kazanmaktır (Guilding ve McManus, 2002; Zeithaml, 2000).

Yükseköğretimde öğrenci sadakâtine etki eden faktörler incelendiğinde sunulan eğitim hizmetinin kalitesi, yükseköğretim kurumunun ve bölümün algılanan imajı (itibarı) ve öğrenci bağlılığı değişkenlerinin ön plâna çıktığ1 görülmektedir (Helgesen ve Nesset, 2007; Köse, 2012). Bir eğitim örgütü olarak yükseköğretim kurumunun sunduğu hizmet eğitim odaklıdır. $\mathrm{Bu}$ değişken öğretim etkinliklerinin etkililiği, kullanılan eğitim-öğretim teknolojileri, iletişim, okulun sâhip olduğu olanaklar ve kullanılan öğretim yöntem ve tekniklerinin güncelliği gibi sunulan hizmetin kalitesine yönelik özellikleri kapsamaktadır (Rashid ve Raj, 2006). Öğrenci sadakâtini etkileyen bir değişken ise kurumun algılanan imajıdır. İmaj bireyden devlet düzeyine kadar hizmet sunan her birimin işinin niteliğine ilişkin algı ve varsayımları önemli ölçüde belirlemektedir (Passow, Fehlmann ve Grahlow, 2005). Bir yükseköğretim kurumu için imaj o kurumun bütün iç ve dış paydaşlarının o kurumun ürettiği hizmetin kalitesine yönelik algısı olarak kavramsallaştırılabilir (Helgesen ve Nesset, 2007; Köse, 2012). Yükseköğretimde öğrenci sadakâtini etkileyen değişkenlerden bir diğeri ise öğrencilerin kurumlarına olan bağgl1ığıdır. Öğrencinin yükseköğretim kurumuna bağlılığ1 genel olarak öğrencinin memnuniyeti, eğitim hizmetinin kalitesine ilişkin alg1s1, kuruma âit olma duygusu ve bir üst eğitim için yeniden kendi kurumunu tercih etme isteğini kapsamaktadır (Strauss ve Volkwein, 2001).

Yükseköğretimde öğrenci sadakâtinin hem kurumsal hem de bireysel düzeyde sonuçlarından bahsetmek mümkündür. Yüksek seviyede öğrenci sadakâtinin sağlanması durumunda, öğrencinin aynı türden bir eğitim hizmetine ihtiyacı ortaya çıktığında yeniden aynı kurumu tercih etmesi beklenmektedir. Bu durum sunulan hizmete ve örgüte karşı oluşan derin sadakâtin 
bir sonucudur (Helgesen ve Nesset, 2007). Bu şekilde yükseköğretim kurumu geliştirdiği insan kaynağından daha uzun süre istifade etme imkânı bulmaktadır. Diğer taraftan yüksek düzeyde öğrenci sadakâtinin sağlanabilmiş olması eğitim talebinin daha tahmin edilebilir bir hâl almasına yardımc1 olmaktadır (Hening-Thurau, Larger ve Hansen, 2001). Yükseköğretimde öğrenci sadakâtinin sağlanmış olması ve beraberinde gelen tahmin edilebilir hizmet talebi yapılacak yatırımlar ve eğitim plânlamasını daha mümkün ve etkili bir biçimde yapılmasına imkân tanımaktadır.

Öğrenci sadakâtiyle ilgili bütün bu kavramsal tartışmaların ötesinde özellikle yükseköğretimde okullaşma oranlarının giderek arttığı ve daha fazla sayıda insanın yükseköğretim düzeyinde eğitim alma talebine sâhip olduğu bilinmektedir (Johnstone, 2004). Daniel, Kanwar ve Uvalić-Trumbić'e (2009) göre dünya genelinde 140 milyonun üzerinde insan yükseköğretim seviyesinde öğrenim almaktadır. Paralel olarak dünya genelinde yükseköğretim kurumlarının sayısı da hızlı bir şekilde artış göstermektedir. Bunun yanında Ekonomik Kalkınma ve İşbirliği Örgütü'nün (OECD) (2013) verilerine göre ülkelerin eğitim için yaptıkları harcamalardan en yüksek payı yükseköğretim almaktadır. 2015 yılı itibariyle 193 yükseköğretim kurumu ve altı milyonun üzerinde yükseköğretim öğrencisinin bulunduğu Türkiye'de eğitim harcamalarında bütün eğitim kademeleri arasında en yüksek pay yükseköğretime ayrılmaktadır. Ekinci (2009) Türkiye'de yükseköğretimde toplam birim öğrenci maliyetinin 15.339 TL olduğu sonucunu sunmaktadır. 1999 y1lında uygulanmaya başlanan Bologna süreci kapsamında oluşturulan “Avrupa Yükseköğretim Alanı”nda bulunan yaklaşık 37.2 milyon öğrenci, farklı ülkelerde eğitim hareketliliğine katılmaları konusunda desteklenmektedir. $\mathrm{Bu}$ türden katılımlar ile yükseköğretim kurumlarının sunduğu eğitim hizmetinin sadece yerel değil; aynı zamanda küresel düzeyde tercih edilir olması ve sunulan hizmete yönelik öğrenci sadakâtinin sağlanmış olması önemli bir konu hâline gelmiştir. Bütün bu nedenlerden dolayı yükseköğretimde öğrenci sadakatinin seviyesinin belirlenmesinin, yapılacak sonraki çalışmaların yönünün belirlenmesinde önemli olduğu düşünülmektedir. İlgili alanyazında öğrenci sadakâtinin teorik yapısını belirlemeye yönelik pek çok araştırma (Helgesen ve Nesset, 2007; Hening-Thurau, Larger ve Hansen, 2001; Martensen ve ark., 2000) bulunmaktadır. Yapılan uzun süreli incelemeler sonunda öğrenci sadakâtinin düzeyinin belirlenmesine yönelik geliştirilen ve en yaygın olarak kullanılan ölçeğin Helgesen ve Nesset (2007) 
tarafından geliştirildiği sonucuna ulaşılmıştır. Bu çalışmanın amacı Helgesen ve Nesset (2007) tarafindan geliştirilen “Öğrenci Sadakâti Ölçeğinin” Türk kültürüne uyarlanmasıdır.

\section{Yöntem}

Öğrencilerin okullarına ne kadar sadakâtli olduklarını belirmek üzere Helgesen ve Nesset (2007) tarafından geliştirilen ölçek yedili likert skalasında olup altı [(i) imkânlar, (ii) hizmet kalitesi, (iii) tatmin, (iv) üniversitenin imajı, (v) bölümün imajı ve (vi) sadakât] faktörden ve toplam yirmi beş (25) maddeden oluşmaktadır.

\section{Evren Örneklem}

Ölçeğin Türkçeye uyarlaması çalışması için aşağıdaki örneklem grupları kullanılmıştır:

1. Orijinal ölçeğin İngilizce maddelerinin uzmanlarca çevrilen Türkçe maddelerle olan uyumluluğunu bir diğer deyişle, dilsel eşdeğerliğini incelemek üzere İngilizce öğretmenliği lisans bölümünden mezun ve eğitim yönetimi alanında doktora seviyesinde olan beş uzmandan istifade edilmiştir.

2. Öğrenci Sadakâti Ölçeği’nin kuramsal evreni üniversite öğrencileridir. Bu kapsamda bu ölçeğin açımlayıcı faktör analizi ve güvenirlik çalışmaları için bu araştırmanın evreni "Yıldız Teknik Üniversitesi Eğitim Fakültesi” 2014-2015 eğitim-öğretim y1lında öğrenim görmekte olan 1.786 öğrenci olarak belirlenmiştir. Tabakalı örnekleme yöntemi ile araştırmaya 270 öğrenci dâhil edilmiştir. Öğrencilerin demografik bilgileri Tablo 1'de sunulmuştur.

3. Türkçeye uyarlanan yeni ölçekte önerilen modelin uygunluğunu test etmek için yapılan doğrulayıcı faktör analizine kolay ulaşılabilir örnekleme yoluyla 247 üniversite öğrencisi dâhil edilmiştir. Öğrencilerin demografik özellikleri Tablo 2'de sunulmuştur. 
Tablo 1. Açımlayıcı Faktör Analizi ve Güvenirlik Çalışmaları Katılımcılarının Demografik Özellikleri

\begin{tabular}{ccccccccccccc}
\hline D̆gşkn & Bölüm & $\boldsymbol{n}$ & $\boldsymbol{\%}$ & Snf & $\boldsymbol{n}$ & $\boldsymbol{\%}$ & Cins. & $\boldsymbol{n}$ & $\boldsymbol{\%}$ & $\begin{array}{c}\text { Tercih } \\
\text { Sirası }\end{array}$ & $\boldsymbol{n}$ & $\boldsymbol{\%}$ \\
\hline $\mathbf{1}$ & İngilizce & 30 & 11.1 & 1. & 79 & 29.3 & Kdn & 203 & 75.2 & 1. & 68 & 27 \\
$\mathbf{2}$ & BÖTE & 30 & 11.1 & 2. & 60 & 22.2 & Erk. & 67 & 24.8 & 2. & 51 & 20.2 \\
$\mathbf{3}$ & PDR & 30 & 11.1 & 3. & 117 & 43.3 & & & & 3. & 57 & 22.6 \\
$\mathbf{4}$ & Türkçe & 30 & 11.1 & 4. & 14 & 5.2 & & & & 4. & 76 & 30.2 \\
$\mathbf{5}$ & Fen Bilgisi & 30 & 11.1 & & & & & & & & & \\
$\mathbf{6}$ & Ilköğretim & 30 & 11.1 & Matematik & & & & & & & & \\
$\mathbf{7}$ & Okul Öncesi & 30 & 11.1 & & & & & & & & & \\
$\mathbf{8}$ & Sinıf & 30 & 11.1 & & & & & & & & & \\
$\mathbf{9}$ & Sosyal Bilgiler & 30 & 11.1 & & & & & & & & & \\
& Toplam & 270 & 100 & & 270 & 100 & & 270 & 100 & & 252 & 100 \\
\hline
\end{tabular}

Tablo 2. Doğrulayıcı Faktör Analizi Katılımcılarının Demografik Özellikleri

\begin{tabular}{|c|c|c|c|c|c|c|c|c|c|c|c|c|}
\hline Dğşkn & Fakülte & $n$ & $\%$ & Snf & $n$ & $\%$ & Cins. & $n$ & $\%$ & $\begin{array}{l}\text { Tercih } \\
\text { Sirası } \\
\end{array}$ & $n$ & $\%$ \\
\hline 1 & Gemi İnşaatı & 22 & 8.9 & 1. & 14 & 5.7 & Kdn & 115 & 46.4 & 1. & 41 & 17.3 \\
\hline 2 & Kimya Matalürji & 61 & 24.7 & 2. & 45 & 18.2 & Erk. & 132 & 53.4 & 2. & 42 & 17.7 \\
\hline 3 & Fen-Edebiyat & 41 & 16.6 & 3. & 97 & 39.3 & & & & 3. & 30 & 12.7 \\
\hline 4 & Mimarlık & 29 & 11.7 & 4. & 91 & 36.8 & & & & 4. & 124 & 52.3 \\
\hline 5 & $\begin{array}{l}\text { İktisadi ve İdari } \\
\text { Bilimler }\end{array}$ & 45 & 18.2 & & & & & & & & & \\
\hline 6 & Eğitim & 20 & 8.1 & & & & & & & & & \\
\hline 7 & Elektrik-Elektronik & 29 & 11.7 & & & & & & & & & \\
\hline 8 & Gemi İnşaatı & 22 & 8.9 & & & & & & & & & \\
\hline \multirow[t]{2}{*}{9} & Kimya Matalürji & 61 & 24.7 & & & & & & & & & \\
\hline & Toplam & 247 & 100 & & 247 & 100 & & 247 & 100 & & 237 & 100 \\
\hline
\end{tabular}

\section{Veri Toplama Araçları}

Uyarlama çalışmasında Öğrenci Sadakâti Ölçeği'nin (Helgesen ve Nesset, 2007) orijinali, İngilizce-Türkçe Çeviri Geçerliği Uygunluk Derecelendirme Formu ve Çeviri ve dil geçerliği sağlanan "Öğrenci Sadakâti Ölçeği”nin Türkçe formu veri toplama araçları olarak kullanılmıştır. Öğrenci Sadakâti Ölçeği, Helgesen ve Nesset (2007) tarafından Norveç’te Aalesund Üniversitesi lisans düzeyindeki 204 erkek, 250 kadın olmak üzere 454 öğrenciden oluşan örneklem üzerinde geliştirilmiştir. Ölçek; 25 madde ve altı 
faktörden oluşmaktadır. Ölçek faktörleri ve her bir faktöre ilişkin Cronbach Alpha değerleri şu şekildedir: imkânlar (facilities) $(\alpha=.78)$, hizmet kalitesi (service quality) $(\alpha=.72)$, doyum (satisfaction) $(\alpha=.91)$, okulun imaj1 (image of university college) $(\alpha=.83)$, çalışma alanının imajı (image of study prog$\operatorname{ram})(\alpha=.85)$ ve sadakât (loyalty) $(\alpha=.82)$.

\section{İşlem}

Ölçeğin uyarlanması sürecinde öncelikle orijinal ölçek maddeleri, İngilizce öğretmenliği lisans bölümünden mezun, eğitim yönetimi alanında en az yüksek lisans seviyesinde olan üç uzman tarafindan birbirlerinden bağımsiz olarak Türkçeye çevrilmiştir. Daha sonra çeviriyi yapan uzmanlar ve araştırmacılar, bir araya gelmiş çevrilen her maddeyi karşılaştırmış ve her madde için sadece bir Türkçe ifade kullanarak Türkçe çeviri formu oluşturmuştur. Ölçeğin dilsel eşdeğerlik çalışması için İngilizce ve Türkçe formu doldurabilecek yeterli üniversite öğrencisi bulunamaması nedeniyle, oluşturulan Türkçe form için İngilizce öğretmenliği lisans bölümünden mezun, eğitim yönetimi alanında en az yüksek lisans seviyesinde olan 5 uzmandan görüş alınmıştır. Bunun için İngilizce orijinal maddeler sol tarafa, Türkçe çeviri maddeleri ise sağ tarafa ve orta kısma ise "Çeviri Geçerliği Uygunluk Derecesi"ni belirten 10 dereceli bir form yerleştirilmiş ve Çeviri Geçerliği Uygunluk Derecesi Formu hazırlanmıştır (Tablo 3).

Tablo 3. Öğrenci Sadakâti Ölçeğinin Çeviri Geçerliği Uygunluk Derecelendirme Formu Örneği

- Öncelikle ölçeğin İngilizce orijinal maddesini daha sonra ise Türkçe maddesini okuyunuz.

- Türkçe maddenin Ingilizce orijinal maddeyi anlam ve içerik yönünden ne derecede karşlladığını; hiç karşılamıyorsa (0); tamamen karşıllyyorsa (10) aralı̆̆ını kullanarak her bir madde için düşüncelerinizi $(x)$ işareti ile belirtiniz.

\begin{tabular}{|c|c|c|c|c|c|c|c|c|c|c|c|c|}
\hline İngilizce Madde & 0 & 1 & 2 & 3 & 4 & 5 & 6 & 7 & 8 & 9 & 10 & Türkçe Madde \\
\hline $\begin{array}{l}\text { Satisfaction with the } \\
\text { university college } \\
\text { compared with an ideal } \\
\text { one }\end{array}$ & 0 & 1 & 2 & 3 & 4 & 5 & 6 & 7 & 8 & 9 & 10 & $\begin{array}{l}\text { İdeal başka bir üniver- } \\
\text { site ile karşılaştırdığ1- } \\
\text { nızda üniversitenizden } \\
\text { memnuniyet }\end{array}$ \\
\hline $\begin{array}{l}\text { Satisfaction with the } \\
\text { university } \\
\begin{array}{l}\text { (spontaneous } \\
\text { ment) }\end{array}\end{array}$ & 0 & 1 & 2 & 3 & 4 & 5 & 6 & 7 & 8 & 9 & 10 & $\begin{array}{l}\text { Üniversitenizden } \\
\text { memnuniyet (anlık bir } \\
\text { değerlendirme yapınız) }\end{array}$ \\
\hline $\begin{array}{l}\text { Probability of atten- } \\
\text { ding the same univer- } \\
\text { sity college if starting } \\
\text { from fresh }\end{array}$ & 0 & 1 & 2 & 3 & 4 & 5 & 6 & 7 & 8 & 9 & 10 & $\begin{array}{l}\text { Yeniden başlasanız } \\
\text { aynı üniversiteyi tercih } \\
\text { etme olasılığınız }\end{array}$ \\
\hline
\end{tabular}


Uzmanlardan gelen geri dönütler doğrultusunda Türkçe forma son hâli verilmiştir. Daha sonra ölçeğin yapı geçerliği çalışmaları yapılmıştır. Yap1 geçerliğini sağlamak için açımlayıcı faktör analizi yapılmıştır. Faktör analizi, tek bir veri setinde, nispeten birbirinden bağımsız; fakat birbiri ile uyumlu veri kümelerini ortaya çıkarmak amacıyla yapılır (Field, 2009; Tabachnick ve Fidell, 1989). Açımlayıcı faktör analizi sonucunda oluşturulan modelin uygunluğunu test etmek için doğrulayıcı faktör analizi (DFA) yapılmıştır. Doğrulayıcı faktör analizi, bir veya birden fazla bağımsız değişkenle bir veya birden fazla bağımlı değişken arasındaki ilişkilerin gerçek verilerle ne derece uyum gösterdiğini değerlendirmeye yönelik bir analizdir (Tabachnick ve Fidell, 1989). Ölçeğin iç tutarlığının belirlenmesi için Cronbach Alpha katsayısı kullanılmıştır. Bunun yanında ölçek faktörleri arasındaki ilişkilerin tespiti için Pearson çarpım momentler korelasyon analizi yapılmıştır.

\section{Bulgular}

\section{Çeviri ve Dilsel Eşdeğerliğe İlişkin Bulgular}

İngilizce Öğretmenliği lisans bölümünden mezun, Eğitim Yönetimi alanında en az yüksek lisans seviyesinde olan beş uzmandan önce orijinal ölçeğin İngilizce maddelerini, daha sonra Türkçe çeviri maddelerini okumaları; Türkçe çevirinin, İngilizce orijinal maddeleri anlam ve içerik yönünden ne kadar karşıladığını değerlendirmeleri istenmiştir. Uzmanların her bir madde için Türkçe çevirisinin uygunluk düzeyini belirledikleri puan dağılımı Tablo 4'te sunulmuştur.

Tablo 4. Öğrenci Sadakâti Ölçeğinin İngilizce Türkçe Uygunluk Puanları

\begin{tabular}{llllll}
\hline Madde no & $\overline{\mathbf{X}}$ & $\mathbf{S}$ & Madde No & $\overline{\mathbf{X}}$ & $\mathbf{S}$ \\
\hline Madde1 & 9.25 & .95 & Madde 14 & $\mathbf{1 0 . 0 0}$ & $\mathbf{. 0 0}$ \\
Madde 2 & 9.75 & .50 & Madde 15 & 9.5 & 1.00 \\
Madde 3 & 7.75 & 2.62 & Madde 16 & 9,75 & .50 \\
Madde 4 & 8.75 & 1.25 & Madde 17 & 9.25 & .95 \\
Madde 5 & 9.75 & .50 & Madde 18 & $\mathbf{1 0 . 0 0}$ & $\mathbf{. 0 0}$ \\
Madde 6 & 9.75 & .50 & Madde 19 & 9.25 & .95 \\
Madde 7 & $\mathbf{1 0 . 0 0}$ & $\mathbf{. 0 0}$ & Madde 20 & 9.25 & .95 \\
Madde 8 & 9.25 & .95 & Madde 21 & 9.25 & .95 \\
Madde 9 & $\mathbf{1 0 . 0 0}$ & $\mathbf{. 0 0}$ & Madde 22 & $\mathbf{6 , 7 5}$ & $\mathbf{3 . 9 4}$ \\
Madde 10 & $\mathbf{1 0 . 0 0}$ & $\mathbf{. 0 0}$ & Madde 23 & $\mathbf{1 0 . 0 0}$ & $\mathbf{. 0 0}$ \\
Madde 11 & 7.00 & 2.44 & Madde 24 & $\mathbf{1 0 . 0 0}$ & $\mathbf{. 0 0}$ \\
Madde 12 & $\mathbf{1 0 . 0 0}$ & $\mathbf{. 0 0}$ & Madde 25 & 8.75 & .95 \\
Madde 13 & 9.5 & 1.00 & & & \\
\hline
\end{tabular}


Her bir maddenin Türkçe çevirisinin orijinal İngilizce maddeyle uygunluk puanları yapılan analiz sonucunda 10.00 ile 6.75 puan arasında olduğu görülmüştür. Çeviri uygunluğu en düşük puan "İş dünyasının (işverenlerin) bölümünüze/çalışma alanınıza ilişkin algıları” ifadesinin yer aldığı madde 22'ye âittir [ $\overline{\mathrm{X}}=6.75$; ss=3.94]. Çeviri uygunluğu puanı düşük olan maddeler üzerinde uzmanlardan gelen geri dönütleri doğrultusunda gerekli düzeltmeler yapılmıştır. Çeviri uygunluğu en yüksek puanlar ise $7,9,10,12$, $14,18,23$ ve 24 . maddelere $[\bar{X}=10.0 ; s s=0.00]$ aittir. Uzmanların değerlendirmeleri sonucunda 25 maddenin 20 'sinin 9 ve üzeri puanlandığı görülmüştür.

\section{Geçerliğe İlişkin Bulgular}

Ölçeğin açımlayıcı faktör analizi için uygunluğunun test edilmesi için Kaiser Meyer Olkin=.837 ve Barlet $\left(\chi^{2}=1847.40, p<.01\right)$ testleri yapılmış ve ölçeğin faktör analizi için uygun olduğu görülmüştür. Ölçeğin faktörleri daha önceden belli olduğu için ve her bir faktörün bağımsız bir şekilde dağ1lacağı düşünülerek Varimax dik eksen döndürme yöntemi tercih edilmiştir (Field, 2009). Varimax dik eksen döndürme tekniği kullanılarak yapılan faktör analizi sonucunda ölçeğin altı faktörden oluştuğu ve ölçeğin toplam varyans miktarının \%72 olduğu görülmüştür. Faktörlerin öz değerleri ve açıkladıkları varyans miktarları Tablo 5'te sunulmuştur.

Tablo 5. Öğrenci Sadakâti Ölçeğinin Faktörlerinin Açıkladıkları Varyans Yüzdeleri ve Özdeğerleri

\begin{tabular}{lcc}
\hline Faktörler & Özdeğer & Açıklanan Varyans \\
\hline Fakültenin imkânları & 1.345 & 8.280 \\
Alınan hizmet kalitesi & 2.271 & 10.569 \\
Hizmet kalitesi & 3.109 & 12.472 \\
Sadakât & 8.090 & 20.669 \\
Çalışma alanının imajı & 1.922 & 10.574 \\
Okulun imajı & 1.412 & 10.027 \\
\hline Toplam & 18.149 & 72.591 \\
\hline
\end{tabular}

Açımlayıcı faktör analizi sonucunda elde edilen faktörler ve faktör yükleri Tablo 6' da sunulmuştur. Stevens (2002), faktör yüklerinin örneklem büyüklügüne göre değiştiğini savunmuştur. Ona göre 50 birimlik bir örneklemle yapılan faktör analizindeki faktör yükü 0.772 ve üzerindeki değerler anlamlı olarak kabul edilirken, 100 birimlik bir örneklemde bu değer 0.512; 
200 birimlik bir örneklemde bu değer 0.364; 400 birimlik bir örneklemde 0.298; 600 birimlik bir örneklemde ise bu rakam 0.21'e kadar düşebilir. Dolayısıyla 270 birimlik bir örneklem üzerinde yapılan ve Tablo 6' da gösterilen faktör analizi sonucunda .913-.473 arasında değişen değerlerin anlamlı olduğu görülmektedir. Her ne kadar okulun imajı ve çalışma alanının imajı faktörlerine yüklenen maddelerde herhangi bir farklılık görülmese de açımlayıcı faktör analizi sonucunda bazı maddelerin Türk kültürüne paralellik gösterecek şekilde farklı faktörlere dağıldığı görülmüştür. Elde edilen bulgular doğrultusunda ölçek sahibinden izin alınmış ve bazı faktörlerin isimleri değiştirilmiştir. Oluşturulan yeni faktör isimleri ve madde örnekleri aşağıdaki gibidir:

- Fakültenin imkânları:

Madde örnekleri:

1) Okuma odalarından memnuniyet

2) Kütüphaneden memnuniyet

- Alınan hizmet kalitesi:

Madde örnekleri:

1) Temizlikten memnuniyet

2) Kantinden memnuniyet

- Hizmet kalitesi:

Madde örnekleri:

1) Öğretim üyelerinin geri dönütlerinden memnuniyet

2) Ders materyallerinin niteliğinden memnuniyet

- Sadakât:

Madde örnekleri:

1) Beklentilerinizle karşılaştırdığınızda üniversitenizden memnuniyet

2) Yeniden başlasanız aynı üniversiteyi tercih etme olasılığınız

- Çalışma alanının imajı:

Madde örnekleri:

1) Yakın çevrenizin/tanıdıklarınızın, bölümünüze/çalışma alanınıza ilişkin algıları

2) İş dünyasının/işverenlerin bölümünüze/çalışma alanınıza ilişkin algilar1

- Okulun imaj1:

Madde örnekleri:

1) Toplumun üniversitenize ilişkin algıları 
2) İş dünyasının/işverenlerin üniversitenize ilişkin algıları

Tablo 6. Öğrenci Sadakâti Ölçeği’nin Açımlayıcı Faktör Analizi Sonuçları

\begin{tabular}{|c|c|c|c|c|c|c|}
\hline $\begin{array}{c}\text { Alt } \\
\text { faktörler }\end{array}$ & $\begin{array}{l}\text { Fakültenin } \\
\text { imkânları }\end{array}$ & $\begin{array}{l}\text { Alınan } \\
\text { hizmet } \\
\text { kalitesi }\end{array}$ & $\begin{array}{l}\text { Hizmet } \\
\text { kalitesi }\end{array}$ & Sadakât & $\begin{array}{c}\text { Çalışma } \\
\text { alanının } \\
\text { imajı }\end{array}$ & $\begin{array}{c}\text { Fakültenin } \\
\text { imajı }\end{array}$ \\
\hline Madde no & Faktör yükü & $\begin{array}{c}\text { Faktör } \\
\text { yükü }\end{array}$ & $\begin{array}{c}\text { Faktör } \\
\text { yükü }\end{array}$ & $\begin{array}{c}\text { Faktör } \\
\text { yükü }\end{array}$ & $\begin{array}{c}\text { Faktör } \\
\text { yükü }\end{array}$ & $\begin{array}{c}\text { Faktör } \\
\text { yükü }\end{array}$ \\
\hline Madde 1 & .859 & - & - & - & - & - \\
\hline Madde 2 & .681 & - & - & - & - & - \\
\hline Madde 4 & .680 & - & - & - & - & - \\
\hline Madde 5 & - & .753 & - & - & - & - \\
\hline Madde 6 & - & .729 & - & - & - & - \\
\hline Madde 7 & - & .913 & - & - & - & - \\
\hline Madde 8 & - & - & .777 & - & - & - \\
\hline Madde 9 & - & - & .715 & - & - & - \\
\hline Madde 10 & - & - & .786 & - & - & - \\
\hline Madde 11 & - & - & .548 & - & - & - \\
\hline Madde 12 & - & - & .473 & - & - & - \\
\hline Madde 3 & - & - & .603 & - & - & - \\
\hline Madde 13 & - & - & - & .851 & - & - \\
\hline Madde 14 & - & - & - & .851 & - & - \\
\hline Madde 15 & - & - & - & .824 & - & - \\
\hline Madde 16 & - & - & - & .788 & - & - \\
\hline Madde 23 & - & - & - & .742 & - & - \\
\hline Madde 24 & - & - & - & .798 & - & - \\
\hline Madde 25 & - & - & - & .561 & - & - \\
\hline Madde 20 & - & - & - & - & .803 & - \\
\hline Madde 21 & - & - & - & - & .902 & - \\
\hline Madde 22 & - & - & - & - & .803 & - \\
\hline Madde 17 & - & - & - & - & - & .857 \\
\hline Madde18 & - & - & - & - & - & .843 \\
\hline Madde 19 & - & - & - & - & - & .679 \\
\hline
\end{tabular}

Açımlayıcı faktör analizi sonucunda ortaya çıkan modelin uygunluğunu test etmek için farklı bir örneklem grubu üzerinde yapılan doğrulayıcı faktör analizine ilişkin uyum indeksleri, Tablo 7'de sunulmuştur. 
Tablo 7. Ölçeğin Doğrulayıcı Faktör Analizi Modeline İlişkin Uyum Parametreleri

\begin{tabular}{cc}
\hline Uyum parametreleri & Katsayı \\
\hline AGFI & .80 \\
CFI & .90 \\
NFI & .84 \\
GFI & .84 \\
RMSEA & .07 \\
$d f$ & 260 \\
$X^{2}$ & 604.6 \\
$X^{2} / d f$ & 2.3 \\
\hline
\end{tabular}

Tablo 7'de görüldügü üzere ölçek için Ki-kare $\left(\chi^{2}\right)$ değeri ve istatistiki anlamll11k düzeyleri $\left[\chi^{2}=604.6, d f=260\right]$ olarak, serbestlik derecesine bağl1 olarak düşük Ki-kare $\left(\chi^{2}\right)$ değeri ise $\left[\chi^{2} /^{d f}=2.3\right]$ olarak hesaplanmıştır. $\chi^{2} /^{d f}$ değerinin üçün altında olması mükemmel uyum, beşin altında olması orta düzeyde uyum anlamına gelmektedir (Kline, 2005). Modele âit uyum indeksleri incelendiğinde RMSEA değerinin .08'den küçük olması iyi uyuma (Tabachnick ve Fidell, 1989); CFI değerinin .90 ve üzerinde olması iyi uyuma (Sümer, 2000); GFI ve AGFI değerlerinin .85 ve üzeri uyuma (Çelik ve Y1lmaz, 2013; Hooper, Coughlan ve Mullen, 2008) işaret eder. Analiz sonucunda elde edilen değerlere göre $[\mathrm{RMSEA}=.07$, AGFI=.80, CFI=.90, $\mathrm{NFI}=.84$, GFI=.84] modellenen yapının faktör yapısının doğruladığını söylenebilir.

Tablo 8. Öğrenci Sadakâti Ölçeğinin Ortalama ve Standart Sapma Puanları ile Faktörler Arasındaki Korelasyon Analizi Sonuçları

\begin{tabular}{lcccccccc}
\hline Faktörler & $\overline{\mathbf{X}}$ & ss & $\mathbf{1}$ & $\mathbf{2}$ & $\mathbf{3}$ & $\mathbf{4}$ & $\mathbf{5}$ & $\mathbf{6}$ \\
\hline 1.Fakültenin imkânları & 9.79 & 3.81 & - & $.360^{*}$ & $.479^{*}$ & $.376^{*}$ & $.184^{*}$ & $.217^{*}$ \\
2.Alınan hizmet kalitesi & 10.32 & 3.56 & - & $.481^{*}$ & $.370^{*}$ & $.124^{*}$ & $.196^{*}$ \\
3.Hizmet kalitesi & 19.51 & 6.78 & & - & $.614^{*}$ & $.207^{*}$ & $.206^{*}$ \\
4.Sadakât & 29.62 & 9.58 & & & - & $.229^{*}$ & $.327^{*}$ \\
5.Çalışma alanının imaj1 & 15.20 & 4.12 & & & & - & $.500^{*}$ \\
6.Fakültenin imaj1 & 17.43 & 3.53 & & & & & - \\
\hline
\end{tabular}

$\mathrm{N}=270, * p<.05$

Yapıs1 doğrulanan ölçeğin faktörleri arasındaki ilişkinin saptanması için Pearson çarpım momentler korelasyon analizi yapılmıştır ve sonuçları Tablo 8'de sunulmuştur. Faktörler arası ilişkilerin $(p<0.05)$ düzeyinde an- 
lamlı olduğu ve en düşük .124 ve en yüksek .500 arasında değiştiği görülmüştür.

\section{Güvenirliğe İlişkin Bulgular}

Güvenirlik çalışması için Cronbach Alfa katsayısı kullanılmıştır. Ö1çeğin faktörlerine ilişkin Cronbach's Alfa değerleri Tablo 9'da sunulmuştur. Güvenirlik analizi sonuçlarına göre faktörlerin Cronbach Alfa değerleri .463 ile .914 arasında değişirken ölçeğin genel güvenirliği .715 olduğu görülmüştür. Zekâ testlerinde güvenirlik katsayısının .8 ve üzeri olması beklenirken, beceri testlerinde bu değerin .7'ye kadar düşebilir. Farklı yapılardan oluşan psikolojik ve algı testlerinde ise bu değerin .7'nin altına kadar düşebileceği belirtilmiştir (Field, 2009; Kline, 1999). Bu bağlamda ölçeğin genel güvenirliğinin .715 olduğu göz önüne alındığında, ölçeğin güvenilir bir ölçek olduğu söylenebilir.

Tablo 9. Öğrenci Sadakâti Ölçeği Güvenirlik Katsayıları

\begin{tabular}{lcc}
\hline Faktörler & Madde sayısı & Cronbach's Alfa \\
\hline Fakültenin imkânlar & 3 & .750 \\
Alınan hizmet kalitesi & 3 & .463 \\
Hizmet kalitesi & 6 & .857 \\
Sadakât & 7 & .914 \\
Çalışma alanının imajı & 3 & .881 \\
Üniversitenin imajı & 3 & .866 \\
\hline Toplam & 25 & .715 \\
\hline
\end{tabular}

\section{Tartışma}

$\mathrm{Bu}$ çalışmada Helgesen ve Nesset (2007) tarafindan geliştirilen Ö $\breve{g}$ renci Sadakâti Ölçeğinin uyarlama, dil geçerliği ve faktör yapısının incelenmesi amaçlanmıştır. Bu amaç doğrultusunda tasarlanan çalışmada, ilk olarak, ölçek maddeleri Türkçeye çevrilmiş ve çeviri geçerliliği incelenmiş; daha sonra da Türkçe ölçek formunun dil ve anlam, içerik geçerliği; açımlayıcı faktör analizi ve doğrulayıcı faktör analizi ve alt ölçekler arasındaki korelasyonlar incelenmiştir. Orijinal ölçekte imkânlar (facilities), hizmet kalitesi (service quality), doyum (satisfaction), okulun imaj1 (image of university college), çalışma alanının imajı (image of study program) ve sadakât (loyalty) olarak belirlenen faktörlerin yapılan açımlayıcı faktör analizi sonucunda Türk kültürüne ve Türkiye'deki yükseköğretim sisteminin yapısına 
paralellik gösterecek şekilde farklı faktörlere dağıldığı görülmüştür. Bu çalışmanın sonuçlarına göre Öğrenci Sadakâti Ölçeğinin faktörleri fakültenin imkânları, alınan hizmet kalitesi, hizmet kalitesi, sadakât, çalışma alanının imaj1, okulun imajı olarak yeniden belirlenmiştir. Benzer bir biçimde Nesset ve Helgesen (2009) Ulusal Müşteri Memnuniyeti İndeksi modelinden yola çıkarak yükseköğretim kurumlarında öğrenci sadakâtinin öğrenme kalitesinden (hizmetin kalitesi) dolaylı da olsa belirleyici bir değişken olduğunu ortaya koymuşlardır. Rojas-Méndez, Vasquez-Parraga, Kara ve Cerda-Urrutia (2009) ise çalışmalarında ise algılanan hizmet kalitesi, memnuniyet, güven ve bağl1lık faktörlerinin öğrenci sadakâtinin belirleyicileri olduğu varsayımı sınanmıştır. Ancak çalışmanın sonucunda algılanan hizmetin kalitesi ve öğrenci memnuniyetinin öğrenci sadakâtini doğrudan etkilemediği ancak güven ve bağlılığ 1 dolaylı olarak etkiledikleri sonucuna ulaşmışlardır. Benzer bir biçimde Alves ve Raposo (2010) ise yükseköğretimde öğrenci sadakâtinin bir boyutu olarak öğrenci memnuniyetinin özellikle kurumun imajı tarafindan belirlendiği sonucuna ulaşmışlardır. Buna göre Alves ve Raposo (2010) kurumun imajının öğrenci sadakâtinin belirleyicilerinden biri olduğunu savunmaktadırlar. Öğrenci Sadakâti Ölçeğinin çeviri ve dil geçerliğini gösteren bu çalışmada, aynı zamanda geçerlik ve güvenirliği kabul edilebilir düzeyde olduğu görülmektedir. Söz konusu ölçek yükseköğretimde öğrenci sadakâtine ilişkin eylemleri ölçümleme düzeyinde ve Türk araştırmacılara uluslararası seviyede çalışmalar yapma olanağı sunmaktadır. Ayrıca bundan sonraki yapılacak çalışmalarda, ölçeğin psikometrik özelliklerinin bütün yönleri ile incelenmesi gereklidir. Ayrıca Türkçeye uyarlanan ölçeğin daha önce geçerliliği ve güvenilirliği sağlanmış ve psikometrik özellikleri sağlanmış diğer ölçeklerle karşılaştırılması yapılmalıdır.

\section{Kaynakça}

Alves, H. ve Raposo, M. (2010). The influence of university image on student behaviour. International Journal of Educational Management, 24(1), 73-85.

doi: http://dx.doi.org/10.1108/09513541011013060.

Brown, T. J., Dacin, P. A., Pratt, M. G. ve Whetten, D. A. (2006). Identity, intended image, construed image, and reputation: An interdisciplinary framework and suggested terminology. Journal of the Academy of Marketing Science, 34(2), 99-106. 
Chun, R. (2005). Corporate reputation: Meaning and measurement. International Journal of Management Reviews, 7(2), 91-109.

Çelik, H. E. ve Yılmaz, V. (2013). Yapısal eşitlik modellemesi: Temel kavramlar, uygulamalar, programlama (2. baskı). Anı Yayınc1lı: Ankara.

Daniel, J., Kanwar, A. ve Uvalić-Trumbić, S. (2009). Breaking higher education's iron triangle: access, cost and quality. Change. Mart/Nisan, 30-35.

Ekinci, C. E. (2009). Türkiye'de yükseköğretimde öğrenci harcama ve maliyetleri. Ĕgitim ve Bilim, 34(154), 119-133.

Field, A. (2009). Discovering statistics using SPSS (3. baskı). Sage Publication: London.

Fornell, C., Johnson, M. D., Anderson, E. W., Cha, J. ve Bryant, B. E. (1996). The American customer satisfaction index: Nature, purpose, and findings. Journal of Marketing, 60, 7-18.

Guilding, C. ve McManus, L. (2002). The incidence, perceived merit and antecedents of customer accounting: an exploratory note. Accounting, Organizations and Society, 27(1), 45-59.

Helgesen, Ø. ve Nesset, W. (2007). Images, satisfaction and antecedents: Drivers of student loyalty? A case study of a Norwegian university collage. Corporate Reputation Review, 10(1), 38-59.

Hennig-Thurau, T., Lager, M. F., and Hansen, U. (2001). Modeling and managing student loyalty: An approach based on the concept of relationship quality. Journal of Service Research, 3(1), 331-344.

Hooper, D., Coughlan, J. ve Mullen, M. (2008). Structural equation modelling: Guidelines for determining model fit. Articles, Electronic Journal of Business Research Methods, 6(1), 53-60.

Johnstone, D. B. (2004). Economics and politics of cost sharing in higher education: Comparative perspective. Economics of Education Review, 23, 403-410. 
Jöreskog, K. ve Sörbom, D. (2001). LISREL 8.51. Mooresvile: Scientific Software.

Kline, T. J. (1999). The team player inventory: Reliability and validity of a measure of predisposition toward organizational team-working environments. Journal for Specialists in Group Work, 24(1), 102-112.

Kline, R. B. (2005). Principle and practice of structural equation modeling (2. baskı). New York, NY: Guilford.

Köse, İ. A. (2012). Yükseköğretim kurumlarında öğrenci sadakâti. Yüksekögretim ve Bilim Dergisi, 2(2), 114-118.

Lam, S. Y., Shankar, V., Erramilli, M. K. ve Murthy, B. (2004). Customer value, satisfaction, loyalty, and switching costs: An illustration from a business-tobusiness service context. Journal of the Academy of Marketing Science, 32(3), 293-311.

Martensen, A., Gronholdt, L., Eskildsen, J. K. ve Kristensen, K. (2000). Measuring student oriented quality in higher education: Application of ECSI method. Sinergie Rapporti di Ricerca, 18(9), 371-383.

Marzo-Navarro, M., Pedraja-Iglesias, M. ve Rivera-Torres, P. (2005). A new management element for universities: Satisfaction with the offered courses. International Journal of Educational Management, 19(6), 505-526.

Nesset, E. ve Helgesen, Ø. (2009). Modelling and managing student loyalty: A study of a Norwegian university college. Scandinavian Journal of Educational Research, 53(4), 327-345.

Doi: 10.1080/00313830903043117.

OECD. (2013). Education at a Glance 2013; OECD Indicators. OECD Publishing.

Oliver, R. L. (1997). Satisfaction: A behavioral perspective on the consumer. McGraw-Hill, New York: Routledge. 
Passow, T., Fehlmann, R. ve Grahlow, H. (2005). Country reputation - from measurement to management: The case of Liechtenstein. Corporate Reputation Review, 7(4), 309-326.

Rashid, T. ve Raj, R. (2006). Customer satisfaction: Relationship marketing in higher education E-learning. Innovative Marketing, 2(3), 24-34.

Reichheld, F. F. (1996). The loyalty effect: The hidden force behind growth, profits, and lasting value. Boston: Harvard Business School Press.

Rojas-Méndez, J. I., Vasquez-Parraga, A. Z., Kara, A. ve Cerda-Urrutia, A. (2009). Determinants of student loyalty in higher education: A tested relationship approach in Latin America. Latin American Business Review, 10(1), 21-39.

Doi: $10.1080 / 10978520903022089$.

Stevens, J. P. (2002). Applied multivariate statistics for the social sciences (4. bask1). Hillsdale, NJ: Erlbaum.

Strauss, L.C. ve Volkwein, J. F. (2001). Predictors of student commitment at two year and four year institutions. Yükseköğretim Çalışma Birliğinin Ylllık Toplantısında sunulmuştur. Richmond, VA.

Sümer, N. (2000). Yapısal eşitlik modelleri. Türk Psikoloji Yazlları, 3(6), 49-74.

Tabachnick, B. G. ve Fidell, L. S. (1989). Using multivariate statistics (2. bask1). New York: Harper Collins Publishers.

Zeithaml, V. A. (2000). Service quality, profitability, and the economic worth of customers: What we know and what we need to learn. Journal of the Academy of Marketing Science, 28(1), 67-85. 